\title{
Role of DNA Methylation in Hypobaric Hypoxia-Induced Neurodegeneration and Spatial Memory Impairment
}

\author{
Rahul Kumar $^{\mathrm{a}}$ Vishal Jain $^{\mathrm{b}}$ Neetu Kushwah ${ }^{\mathrm{a}}$ Aastha Dheer ${ }^{\mathrm{a}}$ \\ Kamla Prasad Mishra ${ }^{c}$ Dipti Prasad $^{a}$ Shashi Bala Singh ${ }^{c}$ \\ a Neurobiology Division, Defence Institute of Physiology and Allied Science (DIAPS), DRDO, New Delhi, India; \\ ${ }^{b}$ Neurophysiology Division, Defence Institute of Physiology and Allied Science (DIAPS), DRDO, New Delhi, India; \\ 'Directorate General Life Sciences, Defence research Development Organisation (DRDO), Government of India, \\ DRDO Bhawan, Rajaji Marg, New Delhi, India
}

\section{Keywords}

Hypobaric hypoxia $\cdot$ DNA methyltransferase $\cdot$ Methyl CpG binding protein 2 . Brain-derived neurotrophic factor . Neurodegeneration

\begin{abstract}
Hypobaric hypoxia $(\mathrm{HH})$ is a major stress factor that is associated with physiological, biochemical, molecular and genomic alterations. Brain is the organ that reacts sensitively to oxygen deprivation, which leads to oxidative stress and cognitive function impairment. Our previous studies have reported that downregulation of brain derived neurotrophic factor (BDNF) leads to neurodegeneration and memory impairment. The aim of the present study was to investigate the effect of $\mathrm{HH}$ exposure on DNA methylation and its regulation in BDNF expression, neurodegeneration and spatial memory impairment. For this purpose, Sprague Dawley rats were exposed to $\mathrm{HH}$ at a simulated altitude of 25,000 feet for 14 days. Real-time polymerase chain reaction was used for transcriptional expression of DNA Methyltransferases (DNMTs) including DNMT1, DNMT3a and DNMT3b, and immunoblotting was used for the transla-
\end{abstract}

tional expression of DNMT1, DNMT3a, DNMT3b, Methyl CpG binding protein 2 (MeCP2), pMeCP2 and BDNF in rat hippocampus. Additionally, neuronal morphology alteration and neurodegeneration in CA1 region of hippocampus were investigated though Cresyl violet (CV) staining and Fluoro-Jade $C$ staining respectively. Results obtained suggested that $\mathrm{HH}$ exposure increased the expression of DNMT1 DNMT3b at the mRNA as well as protein level, whereas no significant change was observed in the level of DNMT3a. Furthermore, the level of $\mathrm{PMeCP} 2$ and BDNF were significantly decreased; however, the expression level of MeCP2 was significantly increased. The CV and Fluoro-Jade C-positive cells were significantly enhanced in the CA1 region of hippocampus in the $\mathrm{HH}$ exposed group as compared to unexposed rats. Thus, the present study concluded that $\mathrm{HH}$ decreases neuronal activation by the upregulation of DNA methylation and MeCP2 and decreased the expression of $\mathrm{pMeCP} 2$, which result in the downregulation of BDNF. The decreased BDNF expression is associated with neuronal loss and spatial memory impairment. This study highlights that DNMT inhibition could be an important therapeutic target for neurodegenerative diseases.

(c) 2018 S. Karger AG, Basel

\section{KARGER}

(C) 2018 S. Karger AG, Basel

E-Mail karger@karger.com

www.karger.com/aon
Dr. Shashi Bala Singh

Distinguished Scientist and Director General (Life Sciences)

Defence Research and Development Organisation (DRDO)

DRDO Bhawan, Rajaji Marg, New Delhi 110011 (India)

E-Mail sbsdrdo@gmail.com, drshashisingh@gmail.com 


\section{Introduction}

Hypobaric hypoxia $(\mathrm{HH})$ has been associated with alterations in neurophysiological functions. Exposure to $\mathrm{HH}$ leads to sleep disturbance [1], oxidative stress [2] and alteration in acetylcholine neurotransmitter [3]. $\mathrm{HH}$ exposure causes cognitive function impairment including learning and memory function, neurodegeneration in CA3 region of hippocampus, glutamate excitotoxicity and high influx of calcium-mediated apoptosis cascade [4]. It also decreases the neurotrophic factor brain derived neurotrophic factor (BDNF), which helps in neuroprotection [21]. It is still unclear how $\mathrm{HH}$ induces neurodegeneration and downregulates the BDNF expression that causes memory impairment. Epigenetic changes could be an important aspect in delineating the mechanism behind $\mathrm{HH}$-induced memory impairment.

Recent data suggest that epigenetic modifications in brain play a principle role in the neuropathogenesis of psychiatric diseases [5], neurodevelopmental [6] and neurodegenerative diseases [7]. The mechanism of epigenetic regulation comprise of DNA methylation, histone modification, nucleosome remodelling and RNAmediated targeting [8]. DNA methylation is the main epigenetic modification, that leads to environment-induced, stable and heritable changes in gene expression. DNA methylation is the covalent addition of methyl group catalysed by DNA Methyltransferase (DNMTs) at cytosine of specially $\mathrm{CpG}$ region of DNA that leads to transcriptional inactivation $[9,10]$. There are different families of DNMTs that have been identified as DNMT $1,3 \mathrm{a}$ and $3 \mathrm{~b}$. The functions of different DNMTs vary with different developmental stages [11]. DNA methylation leads to transcriptional repression by the binding of methyl $\mathrm{CpG}$ binding protein 2 (MeCP2) and methyl CpG binding domain proteins on the methylated DNA. Both the methyl CpG binding domain and $\mathrm{MeCP} 2$ proteins provide a binding site for histone deacetylase (HDAC) at the CpG dinucleotide and lead to the transcriptional repression of the target gene. However, histone acetylation and deacetylation, which are another type of epigenetic modification, catalysed through histone acetyl transferase and deacetyl transferase (HDAC) respectively $[12,13]$.

A previous study reported that reduced levels of methyl transferase in the brain protected it from ischemic injury [14]. Furthermore, another research concluded that DNA methylation plays an important role in the mechanism of memory formation and its storage $[15,16]$; it has also suggested that DNMT inhibitor altered the methyla- tion label on brain plasticity-related genes such as $B D N F$ and reelin. Another study has reported that upregulation of DNA methylation led to contextual fear conditioning and inhibition of DNMT led to the blockage of contextual fear conditioning $[17,18]$. In a study Kishi et al. [19] reported that $\mathrm{MeCP} 2$ is a transcription factor that repressed the expression of targeted genes involved in maturation and function of neurons [20].

Additionally, activity-dependent changes in gene expression occurs due to DNA methylation - for example, changes in BDNF expression due to the phosphorylation of the transcriptional repression complex including $\mathrm{MeCP} 2, \mathrm{CpG}$ and HDAC1 led to the detachment from the BDNF promoter region in addition to the demethylation of $\mathrm{CpG}$ of the BDNF gene result in transcriptional activation. BDNF is a main moderator of the activity-dependent process in brain and is involved in the regulation of neuronal development and plasticity. Another study has suggested that MeCP2 was found to bind at the promoter region of transcription variant III of BDNF and detached due to MeCP2 phosphorylation that result in transcriptional activation and increased expression [21]. There are several in vivo as well as in vitro studies that reported the increased phosphorylation of $\mathrm{MeCP} 2$, which was induced by the neuronal activity in neurons, although, the loss of the MeCP2 phosphorylation associated with the loss of a number of traits of brain functions [22-28]).

There are very few studies on epigenetic changes associated with learning and memory under $\mathrm{HH}$. Thus, in the present study, we evaluated the mRNA as well protein levels of different DNMT1, DNMT3a and DNMT3b enzymes in the hippocampus of $\mathrm{HH}$-exposed and -unexposed rats. Our study concluded that $\mathrm{HH}$ declines neuronal activation by the upregulation of DNA methylation and $\mathrm{MeCP} 2$ and decreased the expression of $\mathrm{pMeCP} 2$, which resulted in the downregulation of BDNF. The decreased BDNF expression is associated with neuronal loss and spatial memory impairment.

\section{Material and Methods}

\section{Animal}

Adult male Sprague Dawley (SD) rats weighing $220 \pm 10$ g were obtained from the animal house of the Institute. All animals were housed in the control environmental condition with a temperature of $23 \pm 2{ }^{\circ} \mathrm{C}$ and humidity $50 \pm 10 \%$. Rats were supplied food and water available ad libitum and the animal room was maintained at a $12 \mathrm{~h} / 12 \mathrm{~h}$ light/dark cycle.

All experiments were performed according to the guidelines of the Committee for the purpose of control and supervision of 
experiments on animals, Government of India. All experimental protocols were approved by the Institutional Ethical Committee for Animal Care and Use.

\section{HH Exposure}

Animals were exposed to chronic $\mathrm{HH}$ at $25,000 \mathrm{ft}(\sim 7,600 \mathrm{~m})$ in an animal decompression chamber by reducing the ambient barometric pressure. The temperature and humidity of the chamber were maintained at $25 \pm 2{ }^{\circ} \mathrm{C}$ and $55 \pm 5 \%$ respectively. Rats were continuously exposed to $\mathrm{HH}$ for 14 days (14 DHH) with 10 15 min interval per day for the supply of water, food and changing of cage housing.

\section{Morris Water Maze}

Morris water maze (MWM) was used for the estimation of spatial memory impairment. MWM was performed according to the study published by Jain et al. [29], with some modification. MWM was composed of a circular pool with height $0.5 \mathrm{~m}$ and diameter $1.6 \mathrm{~m}$ filled with water. The temperature of water was maintained at $22-24^{\circ} \mathrm{C}$. The circular pool was divided into four quadrants, designated as Zone 1, 2, 3, and 4. A hidden platform was placed in Zone 4 known as the platform zone and the platform remained $1 \mathrm{~cm}$ below water. The behaviour and performance of rats were monitored and recorded by a digital camera. The software of this camera was installed in the monitor with ANY Maze software. During the 7 acquisition training periods, rats were placed in water at midpoint of each quadrant. Rats were freely allowed to swim for $60 \mathrm{~s}$ or until they found and climbed on to a hidden platform. If rats were unable to find the hidden platform within $60 \mathrm{~s}$, then it was guided to locate the platform and placed $10 \mathrm{~s}$ on platform. When the performance of all rats became equal, they were subjected for probe trial and memory test before $\mathrm{HH}$ exposure and after $\mathrm{HH}$ exposure for memory retention.

\section{Gene Expression Studies}

RNA Isolation

Total RNA were extracted from snap-freezed hippocampus of the unexposed and hypoxia-exposed rats by the TRIzol regent (Sigma) method. RNA quantification was done by Nano drop (Thermo-fisher) and integrity performed by the running of $2 \mu \mathrm{L}$ RNA on $1 \%$ agarose gel. Single stranded cDNA synthesis was performed according to instructions given by the verso cDNA synthesis kit (AB-1453/A). The compatibility of cDNA synthesis was estimated by using the housekeeping gene as GAPDH.

\section{Real-Time Polymerase Chain Reaction}

Real time polymerase chain reaction (PCR) was used for the quantification of mRNA levels of DNMT1, DNMT3a and DNMT3b genes. The fold change of these genes was estimated by the use of SYBR green master mix (Thermofisher). The forward and reverse primer of specific genes such as DNMT1 F-3-CTGCGGACCCTGGATGTGTT-5, R-3-GGCTGCTGGTTCCCACATCT-5, DNMT3a F3-CATCCGCCACCTCTTCGCTC-5, R-3-CTCTCCGTCCTCTCGTTCTTGG-5 and DNMT3b F-3-GTCATCCGCCACCTCTTCGCTC-5, R-3-CTTCTCTCCGTCCTCTCGTTCTTGG-5 was used for the quantification of cDNA expression in hippocampus. GAPDH gene quantification was used as internal control and normalization of the targeted genes expression. The relative quantification (fold change) of mRNA was estimated by the use of the $\Delta \Delta C T$ method.

\section{Immunoblotting}

Protein Extraction

Rats were anaesthetized with Xylazine ( $10 \mathrm{~mL} / \mathrm{kg}$ body weight) and Ketamine (50 mL/kg body weight) by intraperitoneal (i.p.) injection and decapitated. Immediately whole brains were removed and the hippocampus regions were taken out. They were then snap freezed in liquid nitrogen and stored at $-80^{\circ} \mathrm{C}$ until use. The hippocampus was homogenized in $1.5 \mathrm{~mL}$ micro tube containing the RIPA buffer $(20 \mathrm{mM}$ Tris- $\mathrm{HCl}, \mathrm{pH} 7.5,150 \mathrm{mM} \mathrm{NaCl}$, $1 \mathrm{~mm}$ Na2EDTA, 1 mM EGTA, 1\% NP-40, 1\% sodium deoxycholate, $2.5 \mathrm{~mm}$ sodium pyrophosphate, $1 \%$ Sodium Dodecyl Sulfate (SDS)). A protease inhibitor cocktail (Sigma Aldrich) and a phosphatase inhibitor cocktail (Sigma Aldrich) were added before use. The sample was homogenized by a hand homogenizer followed by centrifugation and collection of supernatant. Protein concentrations of whole tissue homogenates were estimated by the Bradford method.

SDS Page for Immunoblotting

Protein levels in hippocampus were analysed through western blotting and analyses were performed according to previously described methods [30,31]. An equal amount of protein extract was loaded on the SDS page gel that led to the separation of proteins according to their molecular weight. These separated proteins were transferred on to the nitrocellulose membrane followed by 2 -h blocking in 3\% BSA, which was prepared in $0.1 \%$ PBST (tween $20)$. After completion of blocking, the membranes were washed with $0.1 \%$ PBST and incubated with primary antibody anti DNMT1, DNMT3a and DNMT 3b, GAPDH MeCP2, BDNF and pMeCP2for overnight at $4{ }^{\circ} \mathrm{C}$. After the completion of primary antibody incubation, the membranes were washed thrice with $0.1 \%$ PBST followed by incubation in a horseradish peroxidaselinked secondary antibody (1:5000, Millipore) for $2 \mathrm{~h}$ at room temperature. The immunoblots were developed with chemiluminescence reagents (Enhanced chemiluminescence (ECL); Sigma Aldrich) and image captured with MultiDoc-It ${ }^{\mathrm{TM}}$ Imaging System. The band size of appropriated protein was identified by the use of prestained protein ladder (Thermo Scientific). The concentration of the identified protein was quantified through densitometry of immune blots by using Image J analysis software.

\section{Histological Studies}

Cresyl Violet Staining

Rats were anaesthsised with Xylazine and Ketamine and then perfused transcardially with chilled $1 \mathrm{X}$ PBS $(\mathrm{pH}=7.4)$ and $4 \%$ para formaldehyde $(\mathrm{pH}=7.4)$. After perfusion, the whole brain was stored in the same $4 \%$ para formaldehyde for 3-5 days. The brain was dehydrated in the series of 10, 20 and 30\% sucrose dilution. Serial coronal sectioning of 10 and $30 \mu \mathrm{m}$ was performed using cryostat. Coronal sections were taken on gelatin-coated slides and washed with distilled water followed by the incubation in CresylViolet (CV) staining for $10 \mathrm{~min}$. After the completion of incubation, slides were rinsed with water followed by dehydration in graded series of alcohol, that is, 50\%, 70\%, 90\% and absolute alcohol. After dehydration, slides were incubated in Xylazine solution for 2 min and mounted on DPX mounting media.

\section{Fluoro-Jade C Staining}

Apoptotic neurons were estimated by the use of Fluoro-Jade C staining according to the previously described method [32] 
with some modifications. The procedure for cryo-sectioning was used similarly as described in Cresyl violet staining. Sections were immersed in $1 \%$ sodium hydroxide solution and then washed with $70 \%$ ethanol followed by distilled water washing. After washing, sections were incubated in $0.06 \%$ potassium permanganate solution for $20 \mathrm{~min}$ and rinsed twice with distilled water. Then sections were incubated with $0.0001 \%$ FluoroJade C (Millipore, USA) staining for $20 \mathrm{~min}$ followed by 3 times distilled water rinsing. After washing, sections were dried on slides and incubated with Xylene for 2 min and mounted with DPX (Millipore, USA). The Fluoro-Jade C positive cells were manually counted in the CA1 region of $\mathrm{HH}$ exposed and control rats.

\section{Statistical Analysis}

Data was statistically assessed by the unpaired Student $t$ test using graph Pad Prism software version 5. The value were represented as mean \pm SEM of 4 animals for real-time PCR and western blotting and 6 animals per group for histological and behavioural study. The level of significance was set at $p<0.05$.

\section{Results}

Effect of HH Exposure on Spatial Memory Impairment

To explore the potential role of $\mathrm{HH}$ exposure on spatial memory, impairment was evaluated using MWM. After completion of 7 days training, probe trial and memory test were performed before and post $\mathrm{HH}$ exposure. A significant spatial memory impairment was observed in $\mathrm{HH}$-exposed rats as compared to control (unexposed) rats. The probe trial showed that $\mathrm{HH}$ exposure resulted in a significant increase in path-length (Fig. $1 \mathrm{Aa} ; p<0.05$ ) and latency (Fig. 1Ab; $p<0.01$ ) as compared to unexposed rats. Furthermore, memory test after $\mathrm{HH}$ exposure showed that rats spent significantly less time in the targeted zone (Fig. 1Ba; $p<0.05$ ) and number of platform entries (Fig. 1Bb; $p<0.01$ ) as compared to control group.

\section{Effect of HH Exposure on DNMT1, DNMT3a and}

DNMT3b mRNA Expression and Protein Level in

Rat Hippocampus

The mRNA expression of different DNMTs including DNMT1, DNMT3a and DNMT3b in rat's hippocampus was quantified through RT PCR. The bar diagrams in Figure $2 \mathrm{a}-\mathrm{c}$ represent the fold change at the mRNA level of DNMT1, DNMT3a and DNMT3b in the hippocampus. $\mathrm{HH}$ exposure significantly increased the mRNA level of DNMT1 (Fig. 2a; $p<0.01$ ) and DNMT3b (Fig. 2c; $p<$ 0.01 ) as compared to control (unexposed) rats. However, there was no significant change observed in DNMT3a mRNA (Fig. 2b) in HH-exposed rats as compared to control (unexposed) rats.
Furthermore, the protein levels of DNMTs (DNMT1, DNMT3a and DNMT3b) in hippocampus were quantified through western blotting using hippocampus lysates. The band of different DNMTs at appropriate molecular weight on nitrocellulose membrane is shown in Figure 3a. The expressions of DNMT1, DNMT3a and DNMT3b are represented in Figure $3 \mathrm{a}-\mathrm{c}$ respectively. $\mathrm{HH}$ exposure resulted in a significant increase in levels of DNMT1 (Fig. 3b; $p<0.05$ ) and DNMT3b (Fig. 3d; $p<0.001$ ) as compared to control (unexposed) rats, although no significant changes were found in the level of DNMT3a (Fig. 3c) in $\mathrm{HH}$-exposed rats as compared to control (unexposed) rats.

Effect of HH Exposure on MeCP2 and Phosphorylation of MeCP2 at Ser. 421 in Rats Hippocampus

The expression level of total MeCP2 and specific phosphorylation of MeCP2 at Ser. 421 regulates the expression of BDNF, as we found that a band value of about 75 and $51 \mathrm{kDa}$ (Fig. 4a) of pMeCP2 and MeCP2, respectively, was obtained on the nitrocellulose membrane. The densitometry quantification of $\mathrm{pMeCP} 2$ and $\mathrm{MeCP} 2$ showed significant alterations in the level of $\mathrm{MeCP} 2$ and $\mathrm{pMeCP} 2$ in $\mathrm{HH}$ exposed, and control rats were analysed through Student $t$ test (unpaired test) using GraphPad Prism software. The levels of pMeCP2 and MeCP2 are shown in Figure $4 \mathrm{~b}$ and $\mathrm{c}$ respectively. The level of $\mathrm{MeCP} 2$ was significantly increased (Fig. $4 \mathrm{c} ; p<0.01$ ) in the $\mathrm{HH}$ exposed group as compared to control (unexposed) rats. Moreover, phosphorylation of $\mathrm{MeCP} 2$ was significantly decreased (Fig. $4 \mathrm{~b} ; p<0.05$ ) in the $\mathrm{HH}$-exposed group when compared with control rats.

\section{Effect of HH Exposure on the Expression of BDNF}

The expression of BDNF protein was analysed through western blotting in hippocampus. Fig. 5a showed BDNF protein expression in respective groups. The densitometry analysis showed that $\mathrm{HH}$ exposure significantly decreased (Fig. 5b; $p<0.05$ ) the level of BDNF as compared to unexposed rats.

\section{HH Induces Neuronal Morphology Alteration and}

Neurodegeneration in the CA1 Region of Hippocampus

Neuronal morphology alteration is the primary step of apoptotic neurons and loss of neurons associated with memory impairment. CV positive cells and FluoroJade $\mathrm{C}$ positive cells in CA1 region had been shown in Figure $6 \mathrm{a}$, as we found that $\mathrm{HH}$ exposure was associated with neuronal morphology alteration and neurodegeneration in CA1 region. The bar diagram shown in Figure $6 \mathrm{~b}$ and $\mathrm{c}$ 
Fig. 1. Effect of HH exposure on spatial reference memory impairment. $\mathrm{HH}$-exposed spatial memory impairment was estimated through Morris water maze (MWM). A, B Representative traces plot of MWM for probe trial and memory test respectively. The bar diagram (Aa, $\mathbf{A b})$ represent a significant increase in path-length $(* p<0.05)$ and latency $(* * * p<0.01)$ in $\mathrm{HH}$-exposed rats as compared to normoxia rats (control) respectively. The bar diagram of ( $\mathbf{B a}$, $\mathbf{B b})$ represent a significant decrease in the time spent $\left({ }^{*} p<0.05\right)$ and the number of crossing (** $p<0.01)$ in the targeted zone as compared to Normoxia rats (control) respectively. Data represents mean \pm SEM of 4 independent experiments. Student $t$ test was used to calculate significance.

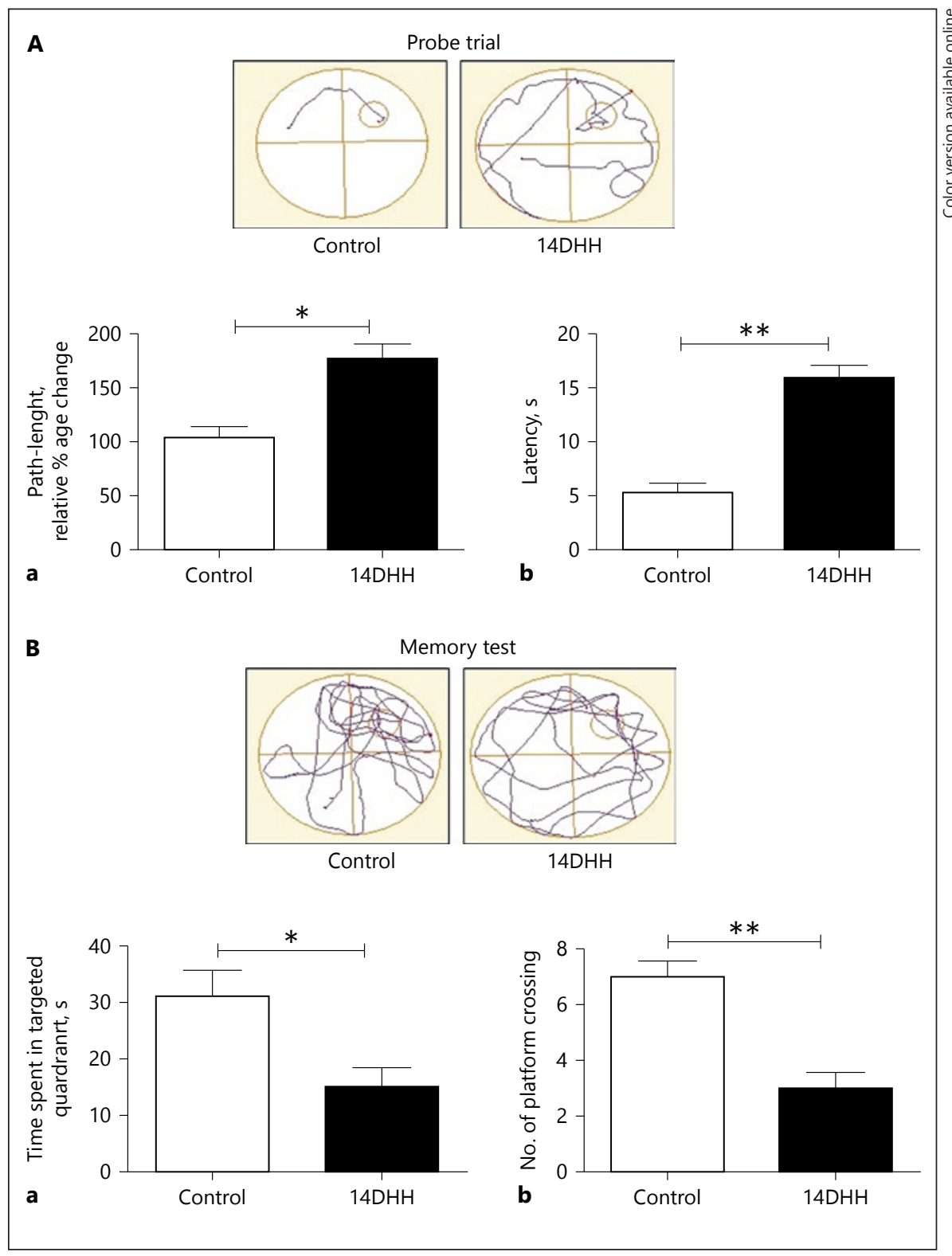

indicates that $\mathrm{HH}$ exposure significantly increased the CV-positive $(p<0.05)$ and Fluoro-Jade C-positive $(p<$ 0.01 ) neurons, respectively, in the CA1 region of hippocampus as compared to control (unexposed) rats.

\section{Discussions}

The effect of $\mathrm{HH}$ on the expression of DNMTs and regulation of $\mathrm{MeCP} 2$ in $\mathrm{BDNF}$ expression is still an enigma. The present study investigated the possible impact of $\mathrm{HH}$ exposure on the level of different DNMTs
(DNMT1, DNMT3a and DNMT3b) at the level of mRNA and protein and its involvement in alterations in spatial memory. Further, studies have been carried out to find the regulation of $\mathrm{MeCP} 2$ phosphorylation through neuronal activation, which regulate the expression of BDNF. BDNF is a neurotrophic factor that works as neuroprotective [33], regulate synaptic plasticity [34] and memory formation. There was an increase in the level of different DNMTs (DNMT1 and DNMT3b) at the mRNA as well as protein level in the hippocampus. $\mathrm{HH}$ decreases the neuronal activation that may have decreased the phosphorylation of MeCP2 at Ser. 421 


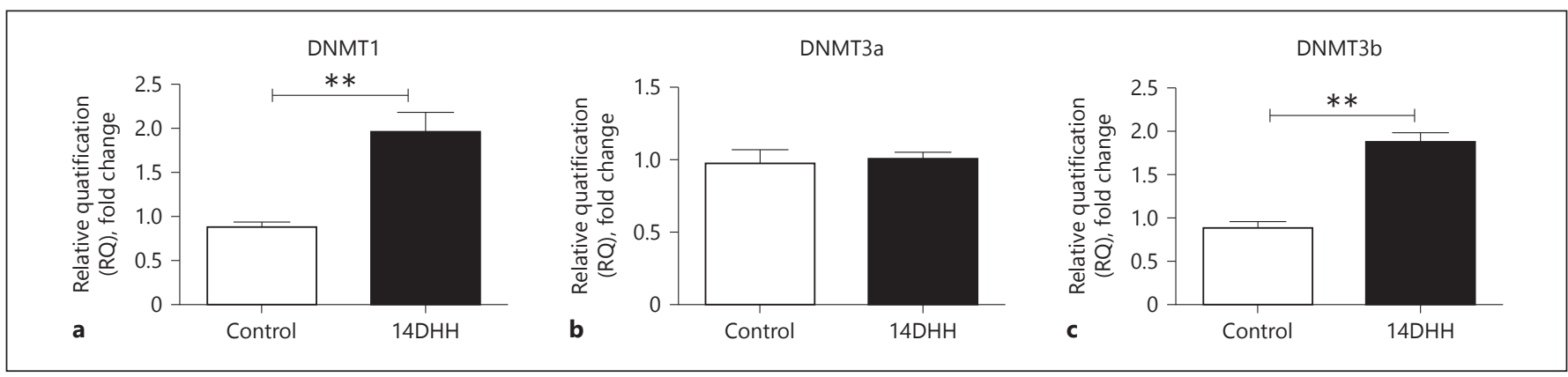

Fig. 2. The effect of HH on the mRNA level of different DNA Methyltransferases (DNMTs) in a rat's hippocampus. The fold change of different DNMTs as DNMT1, DNMT3a and DNMT3b was quantified through real-time PCR in both normoxia and HH-exposed rat's hippocampus. Fold changes of DNMT1, DNMT3a and DNMT3B have been shown through bar diagram as $(\mathbf{a}-\mathbf{c})$ respectively. Fold change in DNMT1 and DNMT3b was increased significantly $(p<$ 0.01 ) in $\mathrm{HH}$-exposed rats as compared to normoxia rats (Control). Data represents mean \pm SEM of 4 independent experiments. Student $t$ test was used to calculate significance; ${ }^{* *} p$ value $<0.01$.

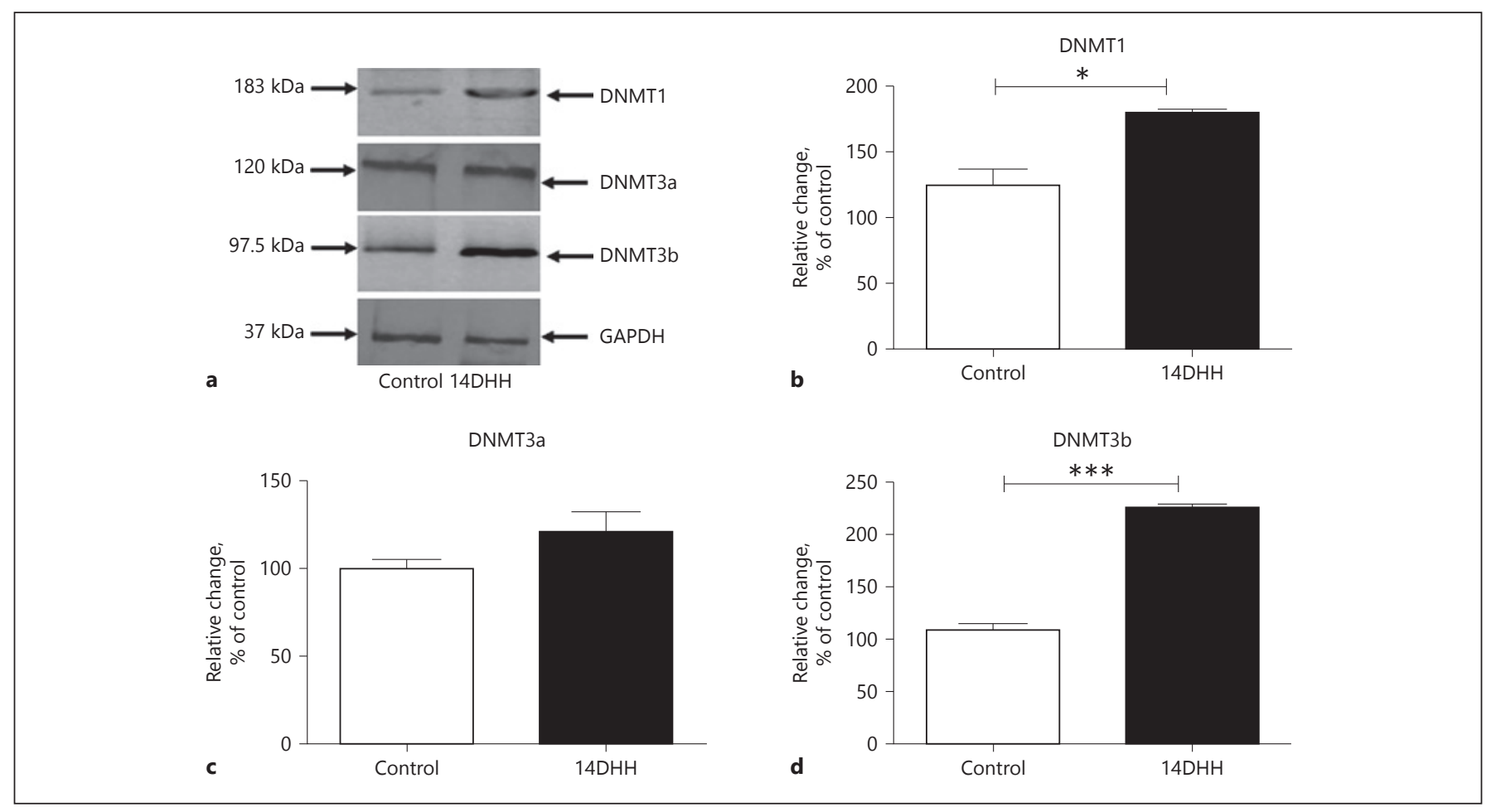

Fig. 3. HH exposure increased the protein level of DNA Methyltransferases (DNMTs) in hippocampus of rats. The levels of DNMTs including DNMT1, DNMT3a and DNMT3b were estimated through western blotting shown in (a). The alterations in the level of DNMT1 (b) and DNMT3b (d) were significantly in-

(pMeCP2-S421). Phosphorylation of MeCP2 regulates the activity-dependent expression of BDNF, and decrease in the expression of BDNF could be associated with neurodegeneration and spatial memory impairment under $\mathrm{HH}$ exposure. creased $\left(* p<0.05,{ }^{* * *} p<0.001\right)$ in $\mathrm{HH}$-exposed rats as compared to normoxia rats (Control), although no significant change was observed in DNMT3a (c). Data represents mean \pm SEM of 4 independent experiments. Student $t$ test was used to calculate significance.

In our results, we have demonstrated that $\mathrm{HH}$ increases the levels of DNMT1 and DNMT3b at both mRNA and protein levels in the hippocampus, whereas there were no significance changes observed in DNMT3a. Our findings are supported by Zhang et al. [35] who reported that hy- 


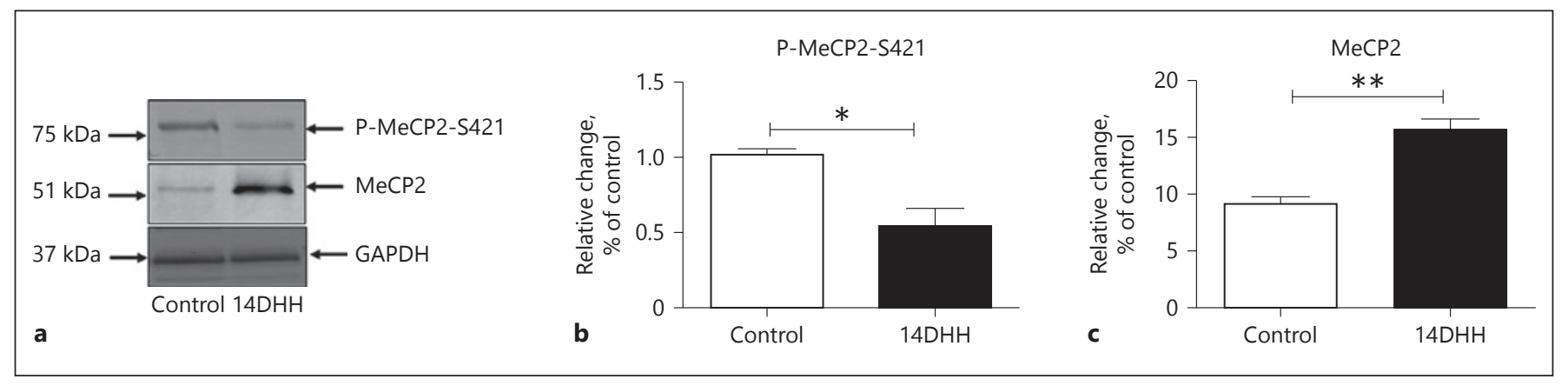

Fig. 4. $\mathrm{HH}$ exposure alters the level of $\mathrm{MeCP} 2$ and $\mathrm{MeCP} 2$ phosphorylation in hippocampus. Alteration in the level of MeCP2 and $\mathrm{MeCP} 2$ phosphorylation at position Ser. 421 was analysed through western blotting in both $\mathrm{HH}$-exposed and normal rats. An equal amount of proteins (in both control and $\mathrm{HH}$ exposed rats) was loaded for both MeCP2 and pMeCP2 (a). A significant decrease in
MeCP2 phosphorylation $\left(\mathbf{b} ;{ }^{*} p<0.05\right)$ and increase in the level of $\mathrm{MeCP} 2\left(\mathbf{c} ;{ }^{* *} p<0.01\right)$ were observed in the $\mathrm{HH}$-exposed group as compared to control rats. Data represents mean \pm SEM of 4 independent experiments. Student $t$ test was used to calculate significance. MeCP2, methyl CpG binding protein 2 .

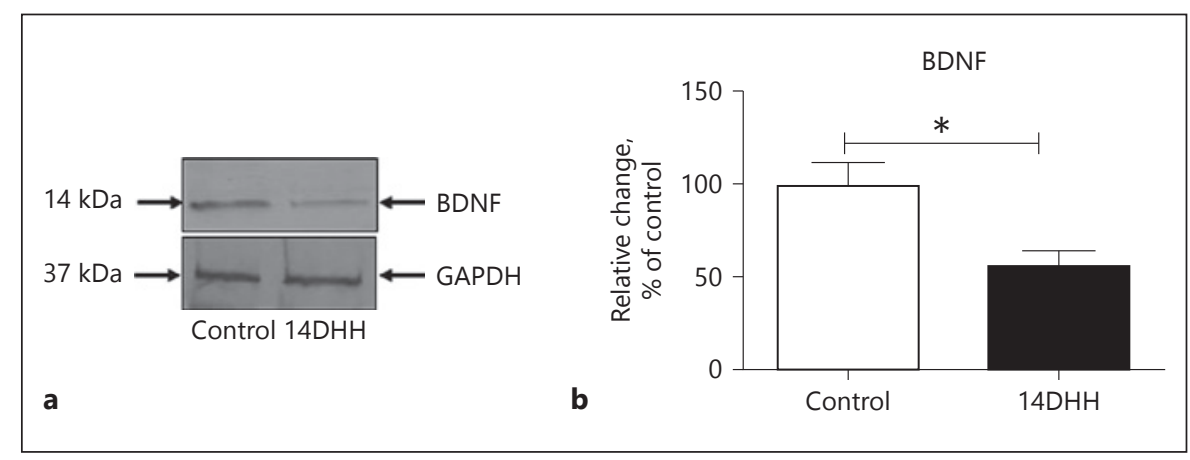

Fig. 5. HH exposure leads to alteration in the BDNF level in hippocampus. Change in the level of BDNF expression was quantified through western blotting in both normoxia (control) and $\mathrm{HH}$-exposed rats. The immunoblotting of BDNF obtained on Nitrocellulose membrane (a) at corresponding molecular weight revealed a significant decrease in the level of BDNF expression in the $\mathrm{HH}$-exposed group of rats $\left(\mathbf{b} ;{ }^{*} p<0.05\right)$ as compared to normoxia rats (Control). Data represents mean \pm SEM of 4 independent experiments. Student $t$ test was used to calculate significance. BDNF, brain derived neurotrophic factor. poxia induces the DNA methylation by increasing the expression of DNMTs in mice hippocampus both at the mRNA and protein levels. DNMT1 predominantly maintained DNA methylation after replication and favourably distinguished hemi methylated DNA [36]. Liu et al. [37] also reported that DNA methylation played an important role in DNA damage and repair under hypoxia/reperfusion-induced brain injuries. So, DNMT1 may play an important role in the methylation of newly incorporated cytosine after repairing [38]. The mechanism behind the upregulation of DNMT1 and DNMT3b under hypoxia is still not clear. A previous report demonstrated that the expression of DNMT1 and DNMT3b was upregulated by hypoxia-induced factor $1 \alpha$ (HIF1 $\alpha)$ through the binding of HIF $1 \alpha$ at hypoxia responsive element site pres- ent at the promoter region of DNMT1 and DNMT3b. The regulation of DNMT1 and DNMT3b through HIF1a provides adaptation to the cell against hypoxia. $\mathrm{HH}$ increases the expression of HIF1a [39], which may induce the expression of DNMT1 and DNMT3b. Changes in the expression of DNMT1 and DNMT3b are associated with the alteration of DNA methylation at the $\mathrm{CpG}$ region of the targeted genes. Increase in DNMTs activity leads to hypermethylation at the promoter of BDNF exon I and IV that result in the decrease of the BDNF mRNA level.

Additionally, we have found out the consequence of DNA methylation on spatial learning and memory in the rat model. During the probe trial, both the pathlength and latency showed an increase after $\mathrm{HH}$ exposure. Furthermore, in memory recognition, the task 


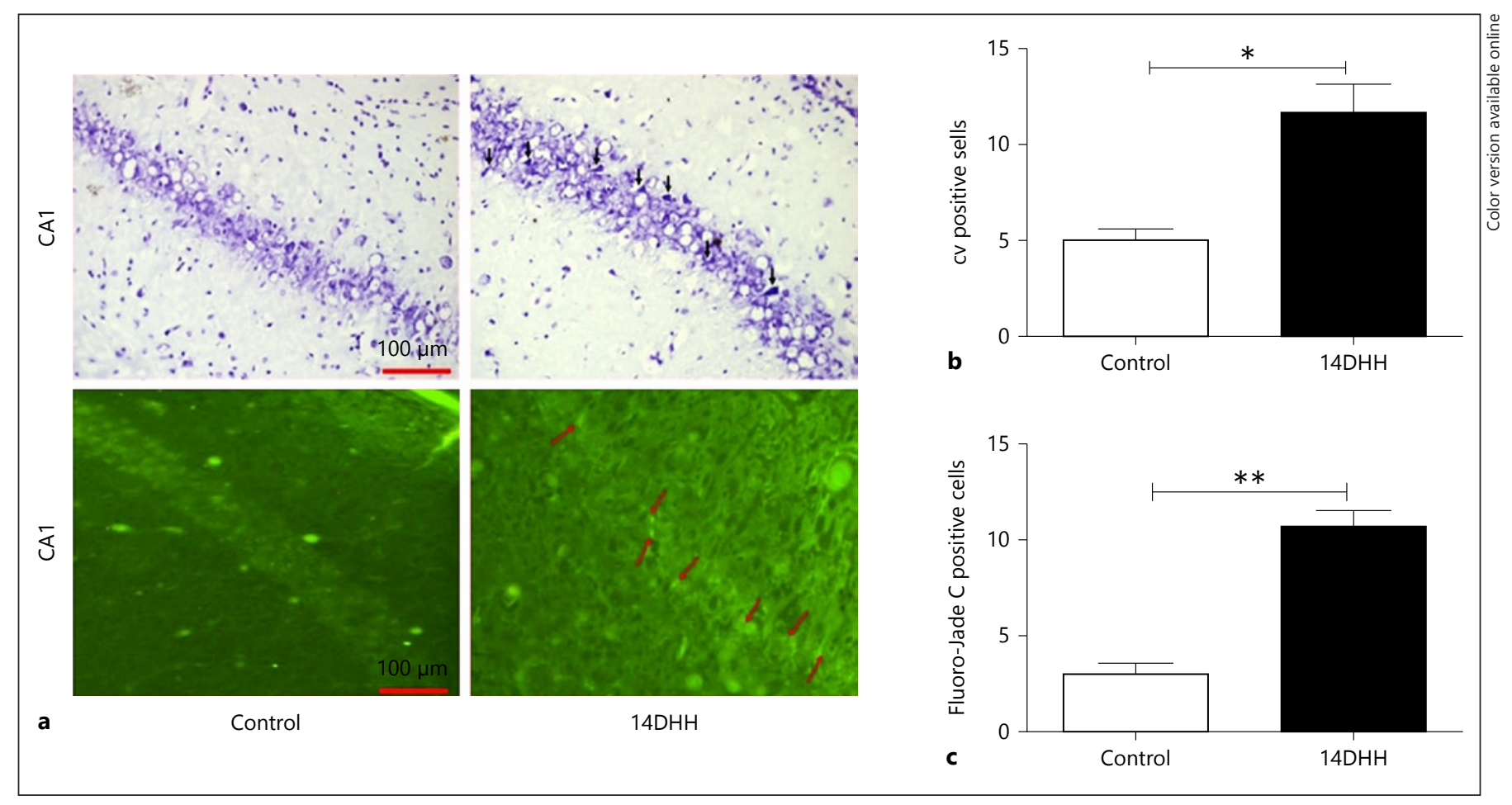

Fig. 6. HH induced neuronal morphology and apoptosis in the CA1 region of hippocampus. Neuronal morphology alteration and apoptotic neurons were examined through CV staining and Fluoro-Jade $\mathrm{C}$ staining, respectively, as shown in (a). A significant increase in the number of $\mathrm{CV}$ positive neurons $(\mathbf{b} ; *<0.05)$ and
Fluoro-Jade C positive neurons $(\mathbf{c} ; * * p<0.01)$ were observed in the HH-exposed group as compared to Normoxia rats (Control). Data represents mean \pm SEM of 6 independent experiments. Student $t$ test was used to calculate significance. $\mathrm{HH}$, hypobaric hypoxia; CV, crystal violet. time spent in the targeted zone and number of crossing in the targeted zone were decreased due to $\mathrm{HH}$ exposure. There may be a possible link between DNA hypermethylation and spatial memory impairment under $\mathrm{HH}$. Our results are in agreement with those of Feng et al. [40] where they have also reported that DNMT1 and DNMT3a play an important role in synaptic plasticity and memory formation.

Next, we found out the possible mechanism that regulates the expression of BDNF through MeCP2 and pMeCP2 in hippocampus. MeCP2 is a main transcriptional repressor protein, unfavourably involved in the maturation of nervous system and also involved in the learning and memory formation [41]. MeCP2 controls the expression of genes through the regulation of chromatin structure and alters the interaction of protein at the promoter site of targeted gene i.e. BDNF etc. There was a significant increase in the level of $\mathrm{MeCP} 2$ in $\mathrm{HH}-$ exposed rats as compared to the unexposed group, which may be due to an increase in DNA methylation. Overexpression of $\mathrm{MeCP} 2$ has been associated with transcriptional inactivation and it plays an important role in neurodegeneration [42]. Additionally, our results revealed that $\mathrm{HH}$-induced neuronal morphology alteration and neurodegeneration as quantified through $\mathrm{CV}$ and Fluoro-Jade C, respectively, in the CA1 region of hippocampus as compared to control rats. Similar findings are also reported by Dastidar et al. [43]. Furthermore, the study had been extended with these initial outcomes and it explored the possible role of MeCP2 and $\mathrm{pMeCP} 2$ in the neurodegeneration as well as regulation of BDNF expression. BDNF genes act as neuroprotective and involve in fear memory $[44,45]$ and spatial memory [46]. NMDA receptor antagonist MK801 leads to demethylation of BDNF exon III and IV promoter in hippocampus [47]. Next, we found the level of phosphorylation of MeCP2 at Ser. 421 (P-MeCP2-S-421) and BDNF in hippocampus of $\mathrm{HH}$ exposed and unexposed rats. Neuronal activation has been associated with the phosphorylation of MeCP2 at Ser. 421 (PMeCP2). The phosphorylation of MeCP2 at the promoter site of $B D N F$ gene regulate different processes like neuronal mor- 
phology alteration, synapse formation and synaptic plasticity [20, 22, 23, 27]. Demethylation of promoter IV of BDNF resulted in an increased mRNA level of BDNF and phosphorylated MeCP2 $[23,48]$. Interestingly, we found the decreased expression of P-MeCP2-S-421, and $\mathrm{BDNF}$ in $\mathrm{HH}$-exposed rats as compared to control rats. Neuronal activity dependent increase in $\mathrm{MeCP} 2$ phosphorylation at ser 421 leads to removal of MeCP2 from BDNF promoter site which further may attribute to increased BDNF expression [21]. A previous reports suggested that the level of P-MeCP2-S-421 is directly correlated with the expression of BDNF [20,49]. So, in the summary, $\mathrm{HH}$ induces DNA methylation that leads to the downregulation of BDNF expression, which may results in neurodegeneration and spatial memory impairment.

\section{Conclusion}

$\mathrm{HH}$ increases the expression of DNMT1 and DNMT3b in hippocampus at the mRNA and protein levels. An increase in the expression of DNMTs is associated with hypermethylation that leads to the transcriptional inactivation of the targeted genes by the binding of MePC2 at the hypermethylated site. Increase in DNA methylation is associated with neuronal damage that leads to neuronal morphology alteration and neurodegeneration in CA1 region of hippocampus. $\mathrm{HH}$ exposure decreased neuronal activation that is associated with a decrease in the phosphorylation of MeCP2 at Ser. 421 at the promotor of BDNF. This resulted in a decreased expression of BDNF, which worked as a neuroprotective and involved in long-term memory (LTM) formation. Therefore, a decrease in the expression of BDNF may lead to the neurodegeneration and spatial memory impairment under $\mathrm{HH}$ exposure. Consequently, MeCP2 and BDNF signaling pathway play an important role in the impairment of hippocampus functions [21].

\section{Acknowledgements}

This study was financially supported by the Defence Research and Development Organization (DRDO), Ministry of Defence, Govt. of India. RK thanks University Grant Commission of India for financial support in the form of JRF and SRF.

\section{Disclosure Statement}

The authors have declared that there are no conflicts of interest to disclose.

\section{References}

1 Saugy JJ, Schmitt L, Fallet S, Faiss R, Vesin JM, Bertschi M, Heinzer R, Millet GP: Sleep disordered breathing during live high-train low in normobaric versus hypobaric hypoxia. High Alt Med Biol 2016;17:233-238.

2 Jain V, Baitharu I, Barhwal K, Prasad D, Singh SB, Ilavazhagan G: Enriched environment prevents hypobaric hypoxia induced neurodegeneration and is independent of antioxidant signaling. Cell Mol Neurobiol 2012; 32:599-611.

3 Muthuraju S, Maiti P, Pati S, Solanki P, Sharma AK, Singh SB, Prasad D, Ilavazhagan G: Role of cholinergic markers on memory function of rats exposed to hypobaric hypoxia. Eur J Pharmacol 2011;672:96-105.

4 Hota SK, Barhwal K, Ray K, Singh SB, Ilavazhagan $\mathrm{G}$ : Ceftriaxone rescues hippocampal neurons from excitotoxicity and enhances memory retrieval in chronic hypobaric hypoxia. Neurobiol Learn Mem 2008;89:522532.

5 Gulchina Y, Xu SJ, Snyder MA, Elefant F, Gao WJ: Epigenetic mechanisms underlying NMDA receptor hypofunction in the prefrontal cortex of juvenile animals in the MAM model for schizophrenia. J Neurochem 2017; 143:320-333.

6 Spiers H, Hannon E, Schalkwyk LC, Bray NJ, Mill J: 5-hydroxymethylcytosine is highly dynamic across human fetal brain development. BMC Genomics 2017;18:738.

7 Griñán-Ferré C, Corpas R, Puigoriol-Illamola D, Palomera-Ávalos V, Sanfeliu C, Pallàs M: Understanding epigenetics in the neurodegeneration of Alzheimer's disease: SAMP8 mouse model. J Alzheimers Dis 2018;62:943963.

8 Dawson MA, Kouzarides T: Cancer epigenetics: from mechanism to therapy. Cell 2012;150:12-27.

9 Baribault C, Ehrlich KC, Ponnaluri VKC, Pradhan S, Lacey M, Ehrlich M: Developmentally linked human DNA hypermethylation is associated with down-modulation, repression, and upregulation of transcription. Epigenetics 2018:1-36.

10 Modrek AS, Golub D, Khan T, Bready D, Prado J, Bowman C, Deng J, Zhang G, Rocha PP, Raviram R, Lazaris C, Stafford JM, LeRoy G, Kader M, Dhaliwal J, Bayin NS, Frenster JD, Serrano J, Chiriboga L, Baital- mal R, Nanjangud G, Chi AS, Golfinos JG, Wang J, Karajannis MA, Bonneau RA, Reinberg D, Tsirigos A, Zagzag D, Snuderl M, Skok JA, Neubert TA, Placantonakis DG: Low-grade astrocytoma mutations in IDH1, P53, and ATRX cooperate to block differentiation of human neural stem cells via repression of SOX2. Cell Rep 2017;21:12671280.

11 Medina-Franco JL, Méndez-Lucio O, Dueñas-González A, Yoo J: Discovery and development of DNA methyltransferase inhibitors using in silico approaches. Drug Discov Today 2015;20:569-577.

12 Schmalbach S, Petri S: Histone deacetylation and motor neuron degeneration. CNS Neurol Disord Drug Targets 2010;9:279-284. Review 2010;9:279-284.

13 Saha RN, Pahan K: HATs and HDACs in neurodegeneration: a tale of disconcerted acetylation homeostasis. Cell Death Differ 2006; 13 : 539-550.

14 Endres M, Meisel A, Biniszkiewicz D, et al: DNA methyltransferase contributes to delayed ischemic brain injury. J Neurosci 2000; 20:3175-3181. 
15 Day JJ, Sweatt JD: DNA methylation and memory formation. Nat Neurosci 2010;13: 1319-1323.

16 Levenson JM, Roth TL, Lubin FD, Miller CA, Huang IC, Desai P, Malone LM, Sweatt JD: Evidence that DNA (cytosine-5) methyltransferase regulates synaptic plasticity in the hippocampus. J Biol Chem 2006;281:15763-15773.

17 Webb WM, Sanchez RG, Perez G, Butler AA, Hauser RM, Rich MC, O'Bierne AL, Jarome TJ, Lubin FD: Dynamic association of epigenetic H3K4me3 and DNA 5hmC marks in the dorsal hippocampus and anterior cingulate cortex following reactivation of a fear memory. Neurobiol Learn Mem 2017;142(Pt A):66-78.

18 Deng JH, Yan W, Han Y, Chen C, Meng SQ, Sun CY, Xu LZ, Xue YX, Gao XJ, Chen N, Zhang FL, Wang YM, Shi J, Lu L: Predictable chronic mild stress during adolescence promotes fear memory extinction in adulthood. Sci Rep 201710;7:7857.

19 Kishi N, Macklis JD: MECP2 is progressively expressed in post-migratory neurons and is involved in neuronal maturation rather than cell fate decisions. Mol Cell Neurosci 2004;27: 306-321.

20 Cohen S, Gabel HW, Hemberg M, Hutchinson AN, Sadacca LA, Ebert DH, Harmin DA, Greenberg RS, Verdine VK, Zhou Z, Wetsel WC, West AE, Greenberg ME: Genome-wide activity-dependent MeCP2 phosphorylation regulates nervous system development and function. Neuron 2011;72:72-85.

21 Han X, Zhang X, Xue Z: Sevoflurane induces long-term memory impairment and increases $\mathrm{MeCP} 2$ phasphorylation in developing mice. Int J Clin Exp Med 2017;10.

22 Chen WG, Chang Q, Lin Y, Meissner A, West AE, Griffith EC, Jaenisch R, Greenberg ME: Derepression of BDNF transcription involves calcium-dependent phosphorylation of MeCP2. Science 2003;302:885-889.

23 Zhou Z, Hong EJ, Cohen S, Zhao WN, Ho HY, Schmidt L, Chen WG, Lin Y, Savner E, Griffith EC, Hu L, Steen JA, Weitz CJ, Greenberg ME: Brain-specific phosphorylation of $\mathrm{MeCP} 2$ regulates activity-dependent BDNF transcription, dendritic growth, and spine maturation. Neuron 2006;52:255-269.

24 Geranton SM, Morenilla-Palao C, Hunt SP: A role for transcriptional repressor methylCpG-binding protein 2 and plasticity-related gene serum- and glucocorticoid-inducible kinase 1 in the induction of inflammatory pain states. J Neurosci 2007;27:6163-6173.

25 Geranton SM, Fratto V, Tochiki KK, Hunt SP: Descending serotonergic controls regulate inflammation-induced mechanical sensitivity and methyl-CpG-binding protein 2 phosphorylation in the rat superficial dorsal horn. Mol Pain 2008;4:35.

26 Deng JV, Rodriguiz RM, Hutchinson AN, Kim IH, Wetsel WC, West AE: MeCP2 in the nucleus accumbens contributes to neural and behavioural responses to psychostimulants. Nat Neurosci 2010;13:1128-1136.

27 Li H, Zhong X, Chau KF, Williams EC, Chang Q: Loss of activity-induced phosphorylation of $\mathrm{MeCP} 2$ enhances synaptogenesis, LTP and spatial memory. Nat Neurosci 2011;14:1001-1008.

28 Mao LM, Horton E, Guo ML, Xue B, Jin DZ, Fibuch EE, Wang JQ: Cocaine increases phosphorylation of MeCP2 in the rat striatum in vivo: a differential role of NMDA receptors. Neurochem Int 59:610-617.

29 Jain V, Baitharu I, Prasad D, Ilavazhagan G: Enriched environment prevents hypobaric hypoxia induced memory impairment and neurodegeneration: role of $\mathrm{BDNF} / \mathrm{PI} 3 \mathrm{~K} /$ GSK3 $\beta$ pathway coupled with CREB activation. PLoS One 2013;8:e62235.

30 Yang L, Mao L, Chen H, Catavsan M, Kozinn J, Arora A, Liu X, Wang JQ: A signaling mechanism from $G$ alpha q-protein-coupled metabotropic glutamate receptors to gene expression: role of the c-Jun N-terminal kinase pathway. J Neurosci 2006;26:971-980.

31 Zhang GC, Mao LM, Liu XY, Parelkar NK, Arora A, Yang L, Hains M, Fibuch EE, Wang JQ: In vivo regulation of Homerla expression in the striatum by cocaine. Mol Pharmacol 2007;71:1148-1158.

32 Xie Z, Enkhjargal B, Wu L, Zhou K, Sun C, Hu X, Gospodarev V, Tang J, You C, Zhang JH: Exendin-4 attenuates neuronal death via GLP-1R/PI3K/Akt pathway in early brain injury after subarachnoid hemorrhage in rats. Neuropharmacology 2018;128:142-151.

33 Wang YC, Sanchez-Mendoza EH, Doeppner TR, Hermann DM: Post-acute delivery of memantine promotes post-ischemic neurological recovery, peri-infarct tissue remodelling, and contralesional brain plasticity. J Cereb Blood Flow Metab 2017;37:980-993.

34 Dandi E, Kalamari A, Touloumi O, Lagoudaki R, Nousiopoulou E, Simeonidou C, Spandou E, Tata DA: Beneficial effects of environmental enrichment on behavior, stress reactivity and synaptophysin/BDNF expression in hippocampus following early life stress. Int J Dev Neurosci 2018:pii:S07365748(17)30320-9.

35 Zhang S, Zhang Y, Jiang S, Liu Y, Huang L, Zhang T, Lu G, Gong K, Ji X, Shao G: The effect of hypoxia preconditioning on DNA methyltransferase and PP1 $\gamma$ in hippocampus of hypoxia preconditioned mice. High Alt Med Biol 2014;15:483-490.

36 Shao G, Zhang R, Zhang S, Jiang S, Liu Y, Zhang W, Zhang Y, Li J, Gong K, Hu XR, Jiang SW: Splice variants DNMT3B4 and DNMT3B7 overexpression inhibit cell proliferation in 293A cell line. In Vitro Cell Dev Biol Anim 2013;49:386-394.

37 Liu PK, Hsu CY, Dizdaroglu M, et al: Damage, repair, and mutagenesis in nuclear genes after mouse forebrain ischemia-reperfusion. J Neurosci 1996;16:6795-6806. Daetstidar et al., (2012).

38 Brooks PJ, Marietta C, Goldman D: DNA mismatch repair and DNA methylation in adult brain neurons. J Neurosci 1996;16:939945

39 Xin X, Dang H, Zhao X, Wang H: Effects of hypobaric hypoxia on rat retina and protective response of resveratrol to the stress. Int J Med Sci 2017;14:943-950.

40 Feng J, Zhou Y, Campbell SL, Le T, Li E, Sweatt JD, Silva AJ, Fan G: Dnmt1 and Dnmt3a maintain DNA methylation and regulate synaptic function in adult forebrain neurons. Nat Neurosci 2010;13:423-430.

41 Betz A, Jayatilaka S, Joshi J, Ramanan S, Debartolo D, Pylypiw H, Franke E: Chronic exposure to benzyl butyl phthalate (BBP) alters social interaction and fear conditioning in male adult rats: alterations in amygdalar MeCP2, ERK1/2 and ERa. Neuro Endocrinol Lett 2013;34:347-358.

42 Subbanna S, Nagre NN, Shivakumar M, Umapathy NS, Psychoyos D, Basavarajappa BS: Ethanol induced acetylation of histone at G9a exon1 and G9a-mediated histone $\mathrm{H} 3$ dimethylation leads to neurodegeneration in neonatal mice. Neuroscience 2014;258:422-432.

43 Dastidar SG, Bardai FH, Ma C, Price V, Rawat V, Verma P, Narayanan V, D'Mello SR: Isoform-specific toxicity of Mecp2 in postmitotic neurons: suppression of neurotoxicity by FoxG1. J Neurosci 2012;32:28462855.

44 Lubin FD, Roth TL, Sweatt JD: Epigenetic regulation of BDNF gene transcription in the consolidation of fear memory. J Neurosci 2008;28:10576-10586.

45 Mizuno K, Dempster E, Mill J, Giese KP Long-lasting regulation of hippocampal BDNF gene transcription after contextual fear conditioning. Genes Brain Behav 2012; 11:651-659.

46 Kuga GK, Muñoz VR, Gaspar RC, Nakandakari SCBR, da Silva ASR, Botezelli JD, Leme JACA, Gomes RJ, de Moura LP, Cintra DE, Ropelle ER, Pauli JR: Impaired insulin signaling and spatial learning in middle-aged rats: The role of PTP1B. Exp Gerontol 2018; 104:66-71.

47 Nelson ED, Kavalali ET, Monteggia LM: Activity-dependent suppression of miniature neurotransmission through the regulation of DNA methylation. J Neurosci 2008;28:395406

48 Neeper SA, Gomez-Pinilla F, Choi J, Cotman C: Exercise and brain neurotrophins. Nature 1995;373:109.

49 Zhong X, Li H, Chang Q: MeCP2 phasphorylation is required for modulating synaptic scaling through mGluR5. J Neurosci 2012;32: 12841-1284 